benefit is consistent for women of all ages, histology, grade, or pelvic nodal involvement; although this benefit may be less for women with the higher stages of disease.

Finally, these results suggest additional benefit from giving further chemotherapy after chemoradiotherapy, which requires further testing in the context of randomised trials.

\title{
REFERENCE
}

1. Cochrane Journal Club. Reducing uncertainties about the effects of chemoradiotherapy for cervical cancer: individual patient data meta-analysis [Clinical summary]. Available from: http://www.cochranejournalclub.com/chemoradiotherapy-for-cervical-cancer-clinical/. Accessed in 2010 (Jan 7).

\section{FURTHER INFORMATION:}

Centro Cochrane do Brasil

Rua Pedro de Toledo, 598

Vila Clementino - São Paulo (SP) - Brasil

CEP 04039-001

Tel. (+55 11) 5579-0469/5575-2970

http://ww.centrocohranedobrasil.org.br/

This section was edited under the responsibility of Brazilian Cochrane Centre

The complete review is available (free access) from: http://www.mrw.interscience.wiley. com/cochrane/clsysrev/articles/CD008285/frame.html.

\section{COMMENTS}

This is an excelent individual patient data meta-analysis for those women diagnosed with cervical cancer which cannot be removed by surgery.

This review endorses the success of chemoradiotherapy, compared with radiotherapy, for overall survival and disease free-survival among women with cervical cancer.

Wagner José Gonçalves. Scientific coordinator, Department of Obstetrics and Gyneco-

logy, Associação Paulista de Medicina (APM), São Paulo, Brazil.

The São Paulo Medical Journal erroneously published a cover headline in the last issue for the article "Efficacy and safety of atypical antipsychotic drugs in treating refractory schizophrenia", which in reality is published in this issue. We apologize to readers of the printed version of the journal 